\title{
Double Helix Relationships in Use and Design of Informing Systems: Lessons to Learn from Phenomenology and Hermeneutics
}

Hans-Erik Nissen, Department of Information and Computer Science, Lund University, Sweden

\author{
Peter Bednar, School of Computing, \\ University of Portsmouth, UK \& \\ Department of Informatics, Lund University, Sweden
}

Christine Welch, Department of Strategy and Business Systems, University of Portsmouth, UK

hans.nissen@telia.com peter.bednar@ics.lu.se christine.welch@port.ac.uk

\section{Abstract}

The theme of this monograph of Informing Science is a dialectic we perceive to exist between meaningful use and reflection upon use. This dialectic between use and reflection on use (or thinking, and thinking about thinking) may be considered in the following way. Each of these elements is subject to change. As reflection triggers change in use, and such change triggers further reflection, a spiral comes about. Lived human experience, and reflection upon that experience, seems to shape a double helix. The monograph contains contributions exploring particular ways in which studies of use could benefit from a relationship to philosophical frameworks such as hermeneutics and phenomenology.

\footnotetext{
Material published as part of this publication, either on-line or in print, is copyrighted by the Informing Science Institute. Permission to make digital or paper copy of part or all of these works for personal or classroom use is granted without fee provided that the copies are not made or distributed for profit or commercial advantage AND that copies 1) bear this notice in full and 2) give the full citation on the first page. It is permissible to abstract these works so long as credit is given. To copy in all other cases or to republish or to post on a server or to redistribute to lists requires specific permission and payment of a fee. Contact

Publisher@InformingScience.org to request redistribution permission.
} 
Keywords: Double Helix, Design, Use, Informing Systems, Phenomenology, Hermeneutics.

\section{Preface}

This editorial is organized in the following way: First there is an introduction to the theme of the monograph followed by an overview of its content. The overview describes perspectives chosen by the different authors and connecting patterns within the monograph. In the next section the editors explain what the monograph offers to the reader and also specifically comment on what it does not offer. The monograph concludes with a glossary that explains some of the specific meanings attributed to some terms used in the monograph.

\section{Introduction}

The original idea for this monograph grew out of a conversation between Peter Bednar and Eli Cohen, the then editor-in-chief of Informing Science: the International Journal of an Emerging Transdiscipline (http://Inform.NU), that took place during the InSITE conference (http://InSITE.NU) at Flagstaff, Arizona in 2005. Peter and Eli discussed approaches to IS research that are based in phenomenology and hermeneutics and Peter outlined his idea of a relationship between use and experience of use in IS, using a double helix metaphor. As a result of this conversation, Eli expressed interest in promoting a monograph, a special series of articles in the journal that focuses on these ideas. The proposal was taken to Professor emeritus Hans-Erik Nissen of Lund University in Sweden, who agreed to become senior guest editor for the suggested monograph. The proposal also included promotion of a ministrand at the following InSITE conference in Manchester in 2006. By that time a number of papers had been received for presentation and panel discussion at the conference. Professor Hans-Erik Nissen introduced the ministrand by elaborating two interpretations of a double helix metaphor based on the double helix of DNA. At the conference, productive sharing of ideas and discussion of phenomenology and hermeneutics took place. These discussions were both enjoyable and useful for the following process of revising the papers.

The theme of this monograph of Informing Science is a dialectic we perceive to exist between meaningful use and reflection upon use (using the double helix metaphor). The perspective taken focuses on mutual learning where the key is the "mutual" part - i.e., that workers and in- 
formation technology analysts must jointly explore, describe, and understand the nature of the work to be supported. This need for mutual learning entails people in both theory and practice.

When we began to think about this theme, it was in part because we felt somewhat isolated in our research perspective and wanted to touch base with other, contemporary, like-minded researchers. We were very pleased therefore, when our call for papers went out, that a number of very different and high quality contributions began to arrive. These contributions came from places as far apart as Bath in the UK, Lund in Sweden, Monash in Australia, Ohio in the USA. They covered widely differing applications of the theme, from organizational problemsolving to multidimensional mapping of conceptual evolution; from field experiences to categorization of knowledge captured in the existing literature. We are privileged that the quality of these papers was matched by very high quality in the reviews provided by academics from around the world, ranging from Japan to Denmark.

Our aim is to acquaint readers with some fundamental ideas from phenomenology and hermeneutics and then to offer them some reports illustrating how such ideas have been adapted to improve practice. The aim is to let readers share the ways of reflecting and acting of the authors. These few examples are indicative of some ways in which theories and practice of Informing Science potentially could benefit from insights in how to apply phenomenological and hermeneutic ideas. However, as Whitaker (in this monograph) warns these ideas are not easily applied in practice, as they have to be adapted creatively to particular situations. In trying to do this, systems analysts and developers need to listen to, observe and learn from the clientele they intend to support.

Since its inception, the relevance of this monograph has been confirmed for us by the appearance of a number of other events and proposals which give some attention to the interests of users, for example, special issues of journals commemorating the works of the late Claudio Ciborra (Avgerou, Hanseth, \& Willcocks, 2006) and the late Enid Mumford (Hirschheim \& Porra, 2007). Later works by Ciborra were clearly linked to Heidegger's perspective of hermeneutic phenomenology (for a discussion of this, please see Depaoli, 2006). More recently, a special issue of the Information Systems Journal has been proposed, entitled 'User - the Great Unknown of Systems Development: Reasons, forms, challenges, experiences and intellectual contributions of 
user involvement' (Ivari, Hannakaisa, \& Pekkola, 2006). Here again, we hear echoes of our concern with a double helix theme. Not only is this phenomenon visible within areas of Natural and Social Sciences but also within Art and Design we can recognize similar concerns. Nicola Hay, for example, in her work on image as a therapeutic catalyst, gives attention to experience and reflection upon experience (Hay, 2001; 2007). The theme of the 2007 European Conference on Information Systems has been 'Rigour and Relevance' (Winter, 2006). We interpret this, again, as a focus on 'thinking and thinking about thinking'. In the United Kingdom, a series of Leverhulme lectures took place at Salford University, delivered by Heinz K. Klein (2006), on the theme of philosophy as practice.

To summarize, the aim of this monograph is to acquaint the readers with some fundamental ideas from phenomenology and hermeneutics. Moreover, it offers its readers some reports illustrating how such ideas have been adapted to improve practice. The authors let the readers share the ways of reflecting and acting. A few examples can only indicate how theories and practice of Informing Science potentially could benefit from insights in how to apply phenomenological and hermeneutic ideas. These ideas are not easily applied in practice as they have to be adapted creatively to particular situations. The perspectives presented and illustrated equip workers, information technology analysts, and researchers with concepts to improve the never ending processes of mutual learning, which use and redesign of information systems entail.

In setting up the agenda for this monograph we wished to encourage contributors to explore a metaphor of double helix. The question then arises: how does this inform our practice as analysts, designers, facilitators and researchers in Informing Systems? Exploring metaphors is not just an exercise by academics without practical consequences. Therefore it has been a pleasure to recognize that the contributors to this monograph have risen to the challenge and brought forward their own interpretations, not only of metaphor in the abstract, but of practical application. The indivisibility of theory and practice has been demonstrated like a red thread throughout the papers. We are pleased to introduce the seven papers and glossary which comprise this monograph:

- 'Using Double Helix Relationships to Understand and Change Informing Systems' by Hans-Erik Nissen. 
- 'Applying Phenomenology and Hermeneutics in IS Design: A Report on Field Experiences’ by Randall Whitaker.

- 'Pedagogy and Process in "Organisational Problem-Solving". by John P. Kawalek

- 'Co-evolution and Contradiction: A Diamond Model of Designer-User Interaction.' by Anja-Karina Pahl and Linda B. Newnes.

- 'The Culture of Information Systems in Knowledge-Creating Contexts: The Role of User-Centred Design.' by Natalie Pang and Don Schauder.

- 'On Categorizing the IS Research literature from a User Perspective'. by Bandula. Jayatilaka, Heinz. K. Klein and J. Lee.

- 'A double helix metaphor for use and usefulness in Informing Systems' by Peter M. Bednar and Christine Welch.

- Glossary of terms used in the monograph on Double Helix. This has been prepared by all the authors in collaboration, under the guidance of Professor Emeritus Hans-Erik Nissen.

All papers are written to stand by themselves. The order in which they are read need not follow their order in the monograph. We hope that the brief presentation of each paper in the overview, together with their abstracts, give some guidance to help readers choose in which order to read them. The whole series of papers is supported by a separate glossary of terms, which forms part of this series.

\section{Overview}

All researchers and practitioners of informing science study and intervene into ways in which people inform themselves and each other. Today, this comprises people-focused research and many artifacts subsumed under the label of information and communication technologies. The editors and authors of this monograph address some novel and innovative perspectives on use, redesign, and understanding of informing systems. Here, the authors test perspectives useful in understanding, and intervening in, dynamic everyday life situations. In order to handle dynamics of this kind, a perspective has to account for history. Artifacts used to facilitate people informing themselves and each other existed 
long before computers. New artifacts incorporate both redesign of earlier ones and, at best, some affordances of their own. However, for people who wish to, or have to, use them they demand a lot of unlearning and learning. Some time ago, in a book shop, the employees had put up the following poster: "Please excuse the mess! We reconstruct our heads. We have just exchanged our computer system for a much better one but it takes time to relearn, so please show us some patience."

To understand redesigned computer support demands time and effort from those "blessed" by it. Both practitioners and researchers know the difficulties involved in redesign, successful implementation and use of information systems. Researchers and consultants have developed many methods and tools to overcome these difficulties. There is a longstanding tradition to deal with these; one significant example is represented by the work of Enid Mumford (see for example Mumford, 1983; 2006). A reawakened interest in a more contemporary setting may be found in an issue of the Journal of the Association for Information Systems, dedicated to Enid Mumford's work (Hirschheim \& Porra, 2006). A recent issue of IEEE (September 2005) illustrates that designing and implementing software is still a risky business (e.g., Charette, 2005). Neither the authors of this monograph nor anybody else can offer a panacea to these complex difficulties. This is illustrated in the constant updating of the Soft Systems Methodology by Peter Checkland and his co-authors (e.g. Checkland \& Poulter, 2006). Here, efforts to combine action with thinking about action are again highlighted, in a systemic context.

When a remedy to handle these difficulties does not succeed, its adherents often suggest using more of the same. This monograph tries to support those who, instead, ask themselves: Why not try something different? The authors report attempts they have successfully tried or are testing to improve redesigning and using informing systems. They also discuss how they arrived at their approaches and their rationale for choosing them.

\section{Perspectives Chosen by Different Authors}

In this section we intend to present the main perspectives chosen by the different authors of this volume. Further we will try to find some patterns connecting them. All contributions focus on practices and theories of evolving processes and on the growth of knowledge. This 
distinguishes them from papers reporting research looking for invariances on which to build technologies. Galtung (1977) discussed the importance for social sciences of distinguishing studies focused on invariance seeking from those focused on invariance breaking. All contributions also share the view that theory and practice stand in a dialectic relationship. What Radnitzky (1970) calls Continental or hermeneuticdialectic (HD) schools of metascience share this position. Whereas, according to Radnitzky (1970), Anglo-Saxon or logical-empirical (LE) schools strictly separate theory from practice. Moreover, HD schools of metascience acknowledge the importance of history, whereas LE schools tend to ignore history.

In the following subsections, we will begin by presenting the authors' concerns and on which sources of fundamental ideas they draw. When we write about from where the authors draw their fundamental ideas we sometimes do not give citations here. However, the reader can find citations in the reference lists of the respective papers. In the subsequent section we will highlight patterns in the authors' papers that appear to us to connect their fundamental ideas.

\section{Nissen}

Nissen calls his paper "Using Double Helix Relationships to Understand and Change Informing Systems". It focuses on concepts and a metaphor intended to improve mutual learning of workers, information technology analysts, and researchers.

The paper first introduces a generalized concept of 'informing science'. It then presents some metascientific perspectives and a metaphor that has explanatory power. A double helix metaphor is presented to highlight some important distinctions. The paper also discusses how metascientific perspectives, and the transdiscipline of informing science, can be seen as related. Finally it argues that computerized models never catch up with ever changing situations. However, people always have to handle the full variety of situations, including those not foreseen during requirements engineering. To address this, the paper suggests balancing requirements engineering with model transparency engineering. Nissen has demonstrated in his paper an effort to combine phenomenology with hermeneutics in IS design. 


\section{Whitaker}

Whitaker's paper "Applying phenomenology and hermeneutics in IS design: A report on field experience" reports experience from 15 years of applying fundamental philosophical ideas in the design of computerized informing systems. He concerns himself with developing systems to support an improved work milieu which better accommodates and facilitates worker praxis. Because his 'praxio-focal' approach emphasizes how the worker engages and interprets data in the context of the work, his analyses and designs are framed with regard to the worker's first person perspective. The relevance of phenomenology and hermeneutics comes from the insights these fields offer for addressing worker experience, cognitive processes, and data interpretations within this first person perspective.

His main theoretical foundations draw on: second order cybernetics including the cybernetics of cybernetics of Heinz von Foerster (1981); the radical constructivism of Ernst von Glasersfeld (1995); and particularly the biology of cognition and enactive cognitive science of Maturana and Varela (Maturana \& Varela, 1980; Varela, 1979; Varela, Thompson, \& Rosch, 1991).

Whitaker has demonstrated the usefulness of his deep fundamental insights in praxis. This makes his contribution a significant one in that it illustrates both (a) the fact that such fundamental ideas can be practically applied and (b) the issues involved in applying them. The importance of practical involvement in learning to apply these kinds of ideas is discussed in Thomas-Meyers and Whitaker (2007).

\section{Kawalek}

Kawalek calls his paper "Pedagogy and process in 'Organisational problem-solving". He concerns himself with supporting middle managers in a number of companies so that they can act successfully as change agents. In the case he reports the managers were organized into teams ('learning sets') to undertake 'organizational problem solving'. In his pedagogy he introduced system constructs from Churchman (1971), particularly those relevant to Hegelian (dialectic) inquiring systems. These helped to structure aspects of the pedagogy. This intervention took participants from the frustrations of cognizing and interacting in an ongoing "here and now" towards reflecting, describing and theorizing on the meaning of experiences. 
The case reported also illustrates features in consulting/research/client relationships. In order to handle these complex relationships Kawalek and his colleagues conducted what he, according to Gibbons (2000), calls "mode 2 type of research." This research acknowledges a close connection between theory and practice as hermeneutic-dialectic schools of meta-science do. A double helix metaphor reminds us of the close interconnection between theorizing and lived experience.

Besides using systems constructs from Churchman (1971) Kawalek builds on ideas from a number of other sources. These comprise complexity theory, Beer's Viable Systems Model, Checkland (1981), and Weick (2001) on sense-making.

\section{Pahl and Newnes}

Pahl and Newnes call their paper "Co-evolution and contradiction: A diamond model of designer-user interaction". In the paper they address the problem of supporting engineers to become more creative in their design tasks. The artifacts designed in their case are not delimited to IT artifacts. Still, where innovation is required in the complex social context of engineering design, the designers, the users, and the researchers also inevitably form a coevolving, mutually emergent informing system. The paper addresses the issue of dialectics which inform designers, users, and researchers in order to improve creativity and innovation.

They bring in new ways of talking and reflecting, and provide some structure to previously unstructured dialogs. This they achieve by introducing simple 'world' models from Mahayana and Vajrayana Buddhism as well as Beer's Viable Systems Model (VSM) and his concept of Team Syntegrity. To establish a reference point for the designer's conversation with users, they consider the issue of establishing a combined 'purpose'. This evolves through the researcher's role in establishing a center for the informing system. Some of Maturana and Varela's arguments are considered in this light.

\section{Pang and Schauder}

Pang and Schauder call their paper "The culture of information systems in knowledge-creating contexts: The role of User-Centred design". The authors focus on the usage of computerized informing systems. They seem concerned with "end users" both as individuals and as members of different groups and communities. Their concern focuses on having 
members of various groups to create, access, contribute to resources, including computer support, collaboratively.

The authors observe in the late 20th century the advent of autonomous, decentralized computing with globally inter-operative Internet. This step they refer to as the "Personal Computing/Internet threshold." They argue that this transition strengthens the existing trends to supplement the techno-centric information systems development with user-centered approaches. In their paper they present an adaptive usercentric development approach to meet this challenge.

The study has been largely based on a research program fuelled by a $\mathrm{PhD}$ study. The study focuses on cultural institutions. The authors see cultural institutions as organizations that promote and support culture, education, and sciences. They do this in a variety of ways: public libraries through the provision of information resources, museums curate and present collections that are representative of communities, or public broadcasting agencies in the provision of rich media-type programs. For the purpose of the authors' research, case studies from museums and libraries were considered. In the desire to study information systems in communities, case studies of cultural institutions in the context of their interactions with communities turned out well-suited to the goals of the study. The communities considered in cultural institutions are key stakeholder groups, such as community groups gathered around one or more interests, or the staff communities.

In their paper the authors report one case fully, an example of a community group whose members share a rural and gender identity. It comprises research on introducing new computerized informing systems in cultural institutions from Australia and Singapore. The case presented comprehensively covered Australia, although there is a good amount of insights borrowed from other case studies in the two countries.

As their theoretical basis the authors explicitly mention Giddens' theory of structuration. This theory they mainly present in a version adapted to information systems research. They are also informed by Orlikowski (1992) and Orlikowski and Robey (1991). For part of their background ideas the authors refer to papers about earlier forms of user-centered design. 


\section{Jayatilaka, Klein, and Lee}

Jayatilaka, Klein, and Lee call their paper "On categorizing the IS literature - A User oriented perspective." In their introduction they present an analogy helping systems analysts to understand the burden of learning they impose on their clientele. This happens, for instance, when systems analysts are suddenly forced to switch to an entirely new development method with a new type of CASE (Computer-Aided Software Engineering) tool.

The paper proposes a way to categorize the information systems research literature by relating the leading theme of each reference to the structurational effects of IT artifacts. The proposed scheme is illustrated by categorizing six IS papers, but in principle is also applicable to books or book chapters. The categorization should enable people to locate contributions from both sides of the paradigmatic divides in the IS literature.

The substantive, cross-paradigmatic classification scheme focuses on the user side of IS development and IS use in organizational and societal contexts. Such a classification can help to identify under-researched areas. It also can be applied to categorize theories underlying information systems research.

The authors briefly discuss critical social theories such as those of Habermas $(1981 / 1984,1981 / 1987)$ as an alternative for their categorization. In this paper, like Pang and Schauder, they decide to build their categories on Giddens' (1984) social theory of structuration.

\section{Bednar and Welch}

In this paper, the authors discuss a dialectic they perceive to subsist between use and reflection on use (or thinking, and thinking about thinking). This dialectic is considered in the following way. Each of the elements is subject to change. As reflection triggers change in use, and such change triggers further reflection, a spiral comes about. The authors provide an overview of relevant philosophical approaches. They suggest a need for phenomenological and hermeneutic perspectives on the complexities of informing systems, viewed as human activity systems (critical systemic thinking). They elaborate upon the double helix metaphor, by contrasting the concepts of 'use', 'usability' and 'usefulness' of informing systems. 
Having introduced this discussion, the authors go on to examine a taxonomy of learning and reflection, and Gregory Bateson's concept of entrapment of mind (Bateson, 1972). An illustration of double bind is provided by reference to the work of Hay (2007) on image as a therapeutic catalyst. Methods of inquiry based in multiple levels of contextual inquiry are suggested as a means to empower individuals to reflect upon their experiences of use. The authors give an example of application in the form of a framework for contextual inquiry, the Strategic Systemic Thinking Framework (Bednar, 2000).

\section{Connecting Patterns}

\section{On some shared patterns and on terminology}

We have become aware of the following patterns, which seem to inform all these contributions. They have all concluded that effective change in human contexts demands more than only applying instrumental reason. However, none of them denies the usefulness of instrumental reason in some confined contexts. In both practicing and theorizing which kind of reason to apply becomes a question of an inclusive "or". All authors seem to listen to the first person perspective of workers affected by computerized parts of informing systems. However, only Whitaker distinguishes this perspective explicitly from the third-person perspective of system analysts.

Interestingly enough the authors have arrived at their positions following different analytical paths. On the way they have encountered rather different terminologies in the sources of their fundamental ideas. To go deeply into these terminological differences falls outside the scope of this paper. The reader is referred to the Glossary that forms part of this monograph. This contains explanations of some specialist expressions, term and abbreviations used by the authors.

\section{More patterns that connect}

As mentioned above, the authors of this monograph have walked different paths to arrive at their fundamental ideas. Two of the papers, that by Whitaker and that by Pahl and Newnes, refer to epistemological ideas stressing embodied minds. These they have fetched from Maturana and Varela.

Pahl and Newnes, addressing how to improve the creativity of engineers, mainly draw on traditions of awareness and knowledge en- 
hancement from Buddhism. They also connect their position on fundamental issues to epistemological ideas of Maturana and Varela. This should come as no a surprise to a reader of Varela, Thompson, and Rosch (1991). These researchers criticize the analytically inclined Western tradition of logical empiricist philosophers. This is particularly the case when it comes to how humans cognize. They draw parallels to what Buddhist traditions teach about mindfulness/awareness. Pahl and Newnes also build on ideas from Beer (1994) on Team Syntegrity, which aims at reaching a profound degree of shared meaning.

Jayatilaka, Klein, and Lee as well as Pang and Schauder borrow fundamental ideas from Giddens (1984). Giddens at the beginning of a chapter called "Consciousness, Self and Social Encounters" writes:

... This will lead directly through an examination of some of the insights which can be drawn from Goffman about interaction between co-present agents. Concern with the body, as the locus of the acting self and as positioned in time-space, is the key linking theme of the material discussed and analysed" ( $p$. 41).

Giddens (1984, pp. 58-67) also acknowledges the importance of the body for human everyday life interactions. This provides a link to ideas on embodied cognizing and acting. Moreover, Giddens several times refers to the work of the late Wittgenstein (1963). Giddens social theory of structuration deserves more attention than it has received from information science/technology researchers, especially his discussion of non discursive practice. Jayatilaka, Klein, and Lee also use some ideas from critical social theory as presented by Habermas (1981/1984, 1981/1987).

Kawalek uses Flood and Carson (1993) on complexity theory. He also refers to Beer's Viable Systems Model (VSM) and to Checkland (1981). With respect to complexity, Flood and Carson (p. 11) distinguish between structured and poorly structured situations. To the latter group they count situations, which involve people as in organizations and societies. Their repertoire to handle complex, dynamic situations comprises Beer's VSM and Checkland's soft systems methodology. They also refer to ideas about living beings fetched from Maturana and Varela. Moreover, they point to the usefulness of highlighting aspects of complex situations by means of metaphors. 


\section{What Does This Series Offer and What Does It Not Offer?}

The fundamental ideas which the editors and authors present and use have built on the works of others. In the last three decades some of them have started to appear in papers on informing systems research. However, few reports on cases where they have become applied and ensuing findings exist.

This monograph reports findings from a number of practical cases, where the fundamental ideas discussed have been applied. These furnish illustrations of ideas otherwise currently only discussed on theoretical levels. This offers some novel ways of framing processes and events in informing science theory and practice. However, the series does not offer another new one size fits framework. The informing science community has seen enough of such frameworks, especially those that seem to promise analytical and empirical salvation/resolution

What this monograph suggests are some new metaphors that may help researchers understand the complexities inherent in using and redesigning informing systems.

These contribute to a continuing dialectic that will help us better make sense of the experience others and we construct in our lives. This comprises understanding cultures in other parts of the globe as well as cultures of our predecessors in both the recent and distant past.

The series does not intend to discuss and pursue philosophical questions per se. Those interested in some fundamental philosophical questions, however, will find a number of references. Some theories not covered include Activity theory (Engeström, 1987; Leont'ev, 1981; Nardi, 1996) and, by and large, Actor Network theory (Callon, 1991, or Latour, 1992). None of the authors here have referenced the former. Actor Network Theory has briefly been alluded to in the paper of Jayatilaka, Klein, and Lee in this monograph.

\section{Concluding Remark}

This series takes the position that contextually different situations will call for different ways to resolve them, all of them explicitly theoretically grounded. The authors offer us a contribution by illustrating philosophically well-grounded approaches that are still rather novel in relation to the IS field. 


\section{Acknowledgements}

All papers have been double blind reviewed several times, by at least three external reviewers in addition to the editors. We would like to acknowledge the contributions of the individuals listed below in this respect. Particular thanks are due to Eli Cohen, whose enthusiastic approach and unflagging support and patience have been greatly appreciated by the editors. Finally, thanks are due to the participants of the two ministrand sessions on Double Helix Relationship of Use and Design at InSITE 2006. The monograph has profited from a number of viewpoints and references, which they contributed.

\section{Reviewers:}

As editors of this monograph we would especially like to acknowledge the help and support of the following academics who have acted as reviewers for the papers submitted to this monograph:

Paolo Depaoli, Department of Science and Technology, Università di Urbino, Italy;

Roger Eglin, Dept. of Creative Technologies, University of Portsmouth, UK;

Umberto Fiaccadori, Dept. of Informatics, Lund University, Sweden;

Christina Fitch, School of Computing, University of Portsmouth, UK;

Sarah Gilmore, Dept. of Human Resource and Marketing Management, Portsmouth Business School, UK;

Gillian Green, School of Computing, Northumbria University, UK;
Parissa Hagharian, Faculty of Liberal Arts, Sophia University, Tokyo, Japan;

Penny Hart, School of Computing, University of Portsmouth, $\mathrm{UK}$;

Andreas Hoecht, Dept. of Strategy and Business Systems, Portsmouth Business School, UK;

Keith Horton, Dept. of Informatics, Napier University, UK;

Vasilios Katos, School of Computing, University of Portsmouth, UK;

Heinz K. Klein, School of Management, Binghampton University, New York, USA;

Jeanette Lemmergaard, Dept. of Marketing and Management, University of Southern Denmark; 
Maria Madlberger, Vienna University of Economics and Business Administration, Austria;

Peter Millard, School of Computing, University of Portsmouth, UK;

Martin Read, Dept. of Strategy and Business Systems, Portsmouth Business School, UK;
Martyn Roberts, Dept. of Strategy and Business Systems, Portsmouth Business School, UK;

Michael Wood, Dept. of Strategy and Business Systems, Portsmouth Business School, UK.

\section{References}

Avgerou, C., Hanseth, O., \& Willcocks, L. (Eds). (2006). Journal of Information Technology, 21(3). Special Issue: Claudio Ciborra and the IS Field: Legacy and Development.

Bateson, G. (1972). Steps to an ecology of mind. New York: Ballantine.

Bednar, P. M. (2000). A contextual integration of individual and organizational learning perspectives as part of IS analysis. Informing Science Journal, 3(3), 145-156. Retrieved from http://inform.nu/Articles/Vol3/v3n3p145156.pdf

Beer, S. (1994). Beyond dispute: The invention of team syntegrity. Chichester: John Wiley \& Sons.

Callon, M. (1991) Techno-economic networks and irreversibility. In J. Law (Ed.), A sociology of monsters. Essays on power, technology and domination (pp. 132-161). London: Routledge.

Charette, R. N. (2005, September). Why software fails. IEEE Spectrum Online, 42-49. Retrieved from http://www.spectrum.ieee.org/sep05/1685

Checkland, P. (1981). Systems thinking, systems practice. Chichester: Wiley.

Checkland, P., \& Poulter, J. (2006). Learning for action: A short definitive account of soft systems methodology, and its use for practitioners, teachers and students. Chichester: Wiley

Churchman, C. W. (1971). The design of inquiring systems. New York: Basic Books.

Depaoli, P. (2006). The influence of Martin Heidegger on Claudio Ciborra's writings. Proceedings of the Italian Conference on Information Systems, ItAIS 2006, Milan, 26-27th October. 
Engeström, Y. (1987). Learning by expanding: An activity - Theoretical approach to developmental research. Retrieved November 24 from http://communication.ucsd.edu/MCA/Paper/Engestrom/expanding/to c.htm

Flood, R. L., \& Carson, E. R. (1993). Dealing with complexity: An introduction to the theory and application of systems science (2nd ed.). New York: Plenum Press.

Galtung, J. (1977). Essays in methodology. Volume 1: Methodology and ideology. Copenhagen: Ejlers.

Gibbons, M. (2000). Mode 2 society and the emergence of context sensitive science. Science and Public Policy, 27(3), 159-163.

Giddens, A. (1984). The constitution of society. Cambridge: Polity Press.

Habermas, J. (1984). The theory of communicative action: Reason and the rationalization of society (Vol 1). (T. McCarthy, Trans.) Boston, MA: Beacon Press. (Original work published 1981.)

Habermas, J. (1987). The theory of communicative action: The critique of functionalist reason (Vol 2). (T. McCarthy, Trans.) Boston, MA: Beacon Press. (Original work published 1981.)

Hay, N. (2001). Problems of individual emergence. Retrieved November, 2006, from

http://www.envf.port.ac.uk/illustration/images/vlsh/pieindex.htm

Hay, N. (2007). Image as a therapeutic catalyst. The Systemist, 29(1), 7-20.

Hirschheim, R., \& Porra, J. (Eds.). (2006). Enid Mumford's contribution to information systems theory and theoretical thinking. Special Issue of the Journal of the Association for Information Systems.

Ivari, J., Hannakaisa, I., \& Pekkola, S. (Eds.). (2006). User - The great unknown of systems development: Reasons, forms, challenges, experiences and intellectual contributions of user involvement. Special issue of Information Systems Journal.

Klein, H. K. (2006). The phenomenological and hermeneutic "Turns": The significance of Husserl's, Schutz's and Gadamer's ideas for information systems research. Third Leverbulme Lecture, University of Sal-ford, Informatics Research Institute, 15th November, 2006.

Latour, B. (1992). Where are the missing masses? The sociology of a few mundane artifacts. In W. E. Bijker \& J. Law (Eds.), Shaping technology/building society. Studies in sociotechnical change. Cambridge, MA: MIT Press.

Leont'ev, A. (1981). Problems of the development of mind. [English translation].

Moscow: Progress Press. (Russian original 1947). 
Maturana, H. R., \& Varela, F. J. (1980). Autopoiesis and cognition: The realization of the living. Dordrecht: D. Riedel. (First published in Chile 1972 under the title De Machinas y Seres Vivos.)

Mumford, E. (1983). Designing human systems for new technology: The ETHICS method. Manchester: Manchester Business School.

Mumford, E. (2006). The story of socio-technical design: Reflections on its successes, failures and potential. Information Systems Journal, 16, 317-342.

Nardi, B. A. (Ed.) (1996) Context and consciousness: Activity theory and bumancomputer interaction. Cambridge, Mass.: The MIT Press.

Orlikowski, W. J. (1992). The duality of technology: Rethinking the concept of technology in organizations. Organization Science, 3(3), 398-472.

Orlikowski, W. J., \& Robey, D. (1991). Information technology and the structuring of organizations. Information Systems Research, 2(2), 143-169

Radnitzky, G. (1970). Contemporary schools of metascience (2nd revised ed.). Gothenburg, Sweden: Akademiforlaget.

Thomas-Meyers, G., \& Whitaker, R. (2007). Apprenticeship in work-centered design: A case study. HSIS 2007: Human Systems Integration Symposium, American Society of Naval Engineers, Annapolis MD, 19 - 21 March.

Varela, F. (1979). Principles of biological autonomy. New York: Elsevier.

Varela, F. J., Thompson, E., \& Rosch, E. (1991). The embodied mind: Cognitive science and human experience. Cambridge, MA: MIT Press.

von Foerster, H. (1981). Observing systems, Seaside, CA: Intersystems Publications.

von Glasersfeld, E. (1984). Radical constructivism. Washington: Falmer Press.

Weick, K. (2001). Making sense of the organisation. Oxford: Blackwell.

Winter, R. (2006). Call for Papers: 15th European Conference on Information Systems: Relevant Rigour - Rigorous Relevance, St. Gallen, Switzerland, 7-9 June 2007

Wittgenstein, L. (1963) Philosophical investigations. (G.E.M. Anscombe, Trans.) Oxford: Basil Blackwell. (First edition 1953.) 


\section{Biographies}

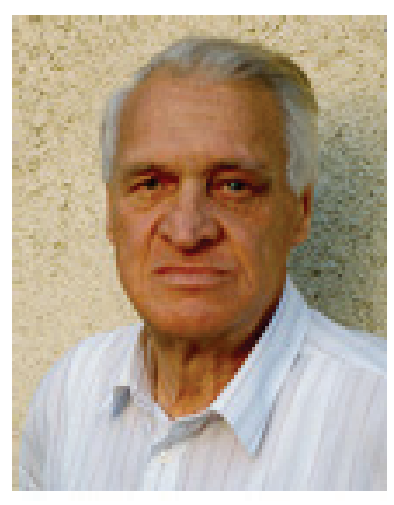

Professor Emeritus Hans-Erik Nissen, since 1991 a senior research fellow at the department of Informatics at Lund University after years of demonstrated research excellence within the information systems field. He graduated in chemistry from the Royal Institute of Technology, Stockholm. He then for many years worked in various positions in the Swedish Pulp, Paper and Timber industry before reentering academia. The seven last years of these he started and headed the first computer center of the Swedish Cellulose Company (SCA).

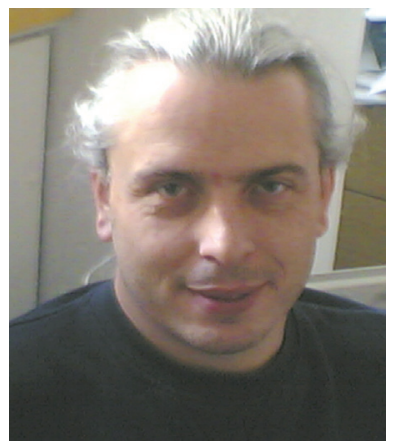

Peter M Bednar is an Engineer and Senior Lecturer with several years of experience from industry in systems analysis and development. Since 1997, his main occupation is academic. His research covers contextual analysis, organizational change and information systems development, and he has published several book chapters and many articles in these fields. He is currently a member of the IS group at the School of Computing at the University of Portsmouth, UK and is also affiliated to the Department of Informatics at Lund University, Sweden.

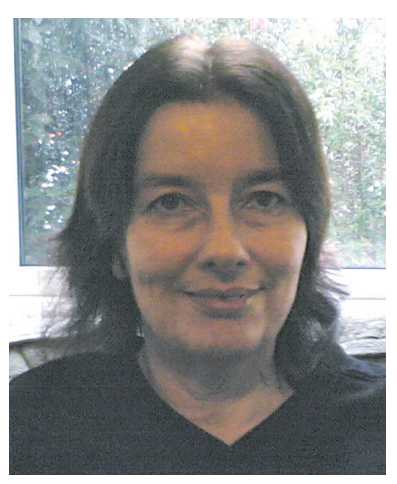

Christine Welch is a Principal Lecturer in the Department of Strategy and Business Systems, part of the Business School at the University of Portsmouth, UK. Her research interests include critical systemic thinking, contextual analysis and organizational change, and she has published several book chapters and articles in these fields. She is convenor of the Southern Regional Centre of the UK Systems Society. 